\title{
Opinion about Advances of Chitosan in Pharmaceutical Field: From Past to Now
}

\author{
Delattre $C^{*}$ \\ Institute Pascal UMR CNRS 6602, Université Clermont Auvergne, France
}

*Corresponding author: Delattre C, Institut Pascal UMR CNRS 6602, Université Clermont Auvergne, F-63000 Clermont-Ferrand, France Submission: 眥September 18, 2017; Published: 侮 October 25, 2017

\begin{abstract}
From long time, scientists are looking for natural biomolecules in order to discover new pharmaceutical agents. Therefore polysaccharides which are natural molecules from several biotopes (microbial, plant, algae, fungi, animals, and insects) constitute a very large potential of application for medical treatment. Among them, chitosan a deacetylated form of chitin (one of the most abundant polysaccharide in the world) and its derivatives are probably the pharmaceutical polysaccharides of now and the future due to intrinsic biological and chemical properties. In this present editorial opinion we describe the mainly commonly chemical and enzymatic processes investigated to generate chitosan and derivatives with pharmaceutical efficiency such as antitumoral agent, antimicrobial agent, antioxidant agent and tissular engineering agent.
\end{abstract}

Keywords: Bioactivity; Chemical derivatives; Chitosan; Pharmaceutical; Polysaccharide

Chitosan and its Derivatives: What are the Main Synthesis Strategies?

From past to tomorrow natural bioactive molecules have fascinated researchers around the world. We cannot talk about biomolecules without talking about polysaccharides which are biopolymers broadly found in the nature such as from animals, plants, fungi and bacteria [1]. Generally, polysaccharides possess diverse biological and technical functions such as cell wall architecture (cellulose or chitin), the storage of the energy (starch), and gel formation (pectins, alginates, glycosaminoglycans). All these properties are essentially valorized and exploited in cosmetic and food industries. Nevertheless, lots of studies from the last two decades have largely suggested that polysaccharides have functional properties directly implicated in the biological responses for pharmaceutical applications. In this context, with starch and cellulose, chitosan which is synthesized by deacetylation of chitin (Figure 1) is probably ranked in the top 3 of the more published polysaccharides in the last scientific publications from literature.

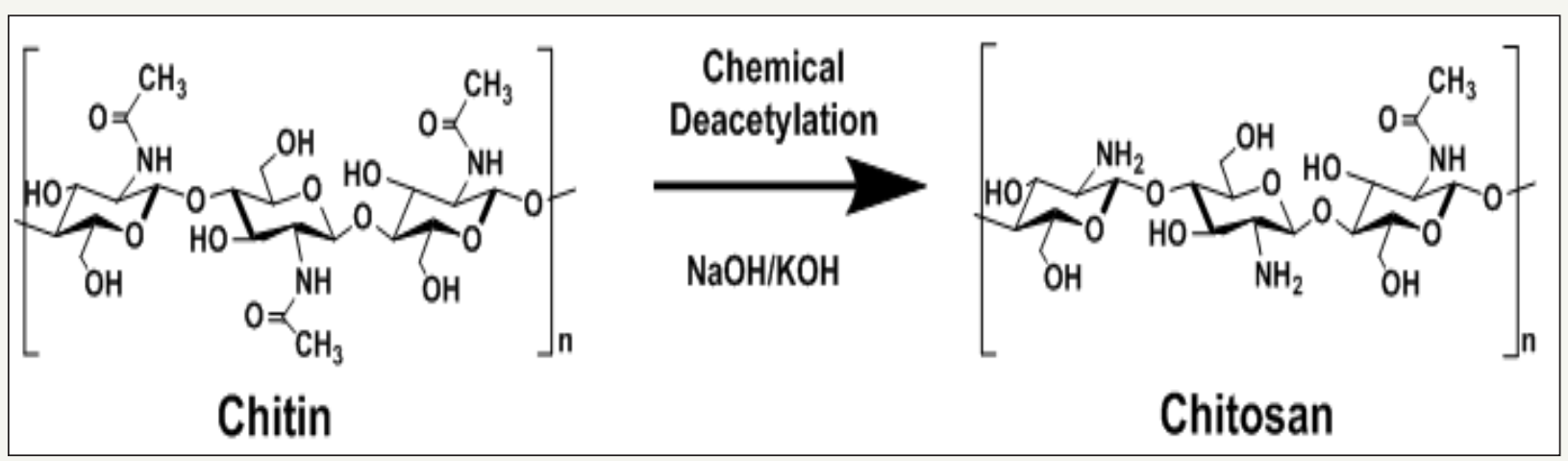

Figure 1: Production of chitosan using deacetylation of chitin in alkakine media ( $\mathrm{NaOH}$ and/or $\mathrm{KOH})$.

As shown in (Figure 1), chitosan is produced from alkali $\mathrm{N}$-deacetylation of chitin a natural polysaccharide constituted by $\beta$-(1,4)-2-acetamido-2-deoxy-D-glucose repeating units patterns. Chitin is certainly after cellulose the most abundant polysaccharides found in lot of natural biotope such as insect cuticles, fungi, crustacean shells and mollusks. In a recent publication, Mati et al. [2] have given a very interesting overview of chitin and chitosan characteristics and more especially about physical and chemical properties of these two important polysaccharides. In summary, authors indicated that nearly 1000 to 1500 tons of chitin is 
generally produced each year in the world. The main difference that characterized chitosan is the amount of $\mathrm{N}$-acetyl glucosamine groups. In fact chitin is a high $\mathrm{N}$-acetylated polysaccharide (near to $90-95 \% \mathrm{~mol}$ ) whereas chitosan contain low amount of $\mathrm{N}$-acetyl glucosamine groups (between $30-40 \% \mathrm{~mol}$ ) [2-5]. Due to the low amount of acetylated glucosamine, chitosan is extremely soluble in acid solution which allows a large applications domain thanks to its exclusive greatly cationic polysaccharidic structure. Chitosan is then considered as a non-toxic renewable polysaccharide with very high biocompatibility and biodegradability $[2,4,5]$. In order to improve and try to modulate the biological activities, chitosan constitutes a perfect model for specific chemical and/or enzymatic modifications. In that way, lots of publications have been published these last year's [4,6-16]. Generally, in a chemical point of view, chitosan is very reactive due to the presence of active functions such as primary amine groups (-NH2) and hydroxyl groups $(-\mathrm{OH})$.

Therefore, as summarized in (Figure 2), chemical modifications of chitosan such as:

a) N-acylation,

b) N-alkylation,

c) N-quaternization and,

d) C-6 carboxylation are certainly the main functionalization described in literature.

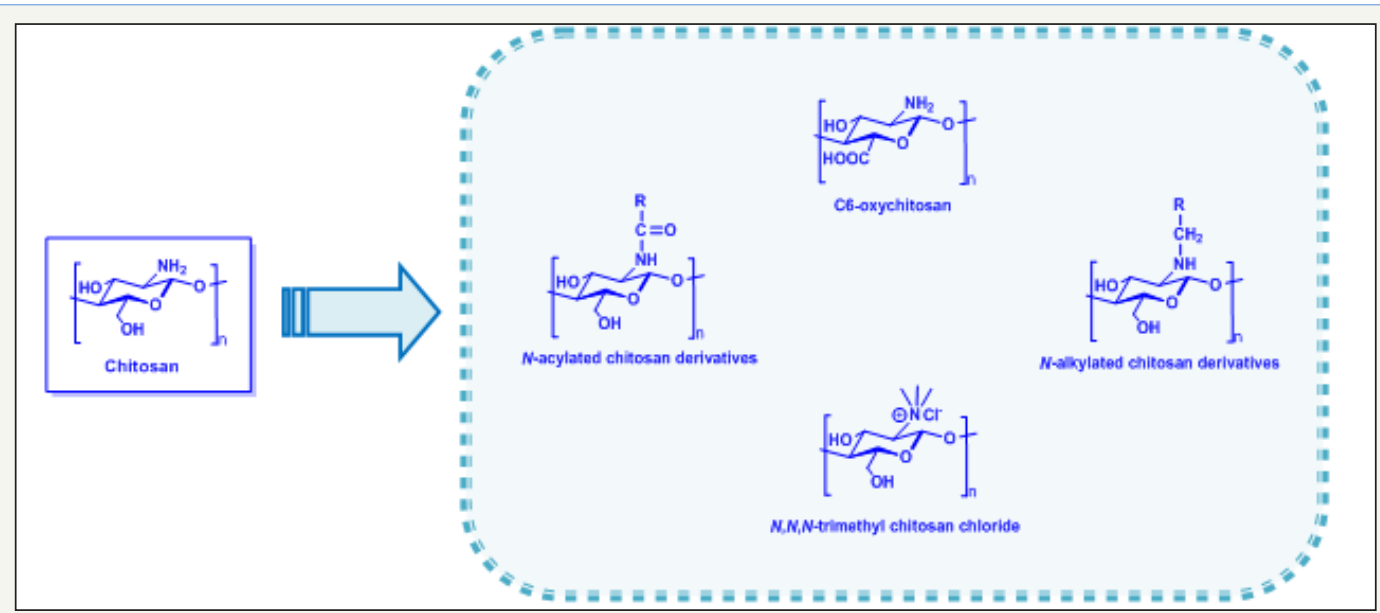

Figure 2: Main chemical modification of chitosan to generate bioactive chitosan derivatives.

All these chemical modification of chitosan have been carried in order to regulate the global cationic charge of chitosan via the $-\mathrm{NH}_{3}{ }^{+}$function to increase the high solubilization of chitosan and its derivatives for a large range of $\mathrm{pH}$ (from acid to alkaline). That's why the synthesis of $\mathrm{N}, \mathrm{N}, \mathrm{N}$-trimethyl chitosan chloride and others derivatives by using a specific quaternization mechanism of the $-\mathrm{NH}_{2}$ group is the most described in literature [4,13-16]. In the following paragraph, some examples of bioactive chitosan derivatives are presented for theirs putative pharmaceutical applications.

\section{Pharmaceutical Applications}

For more than a decade, chitosan and its derivatives continues to be the preferred candidate used to develop biologically active polysaccharides. In fact, some publications reported the efficiency of chitosan in lot of field such as pharmaceutics and medicine [4-6].

More particularly as shown in (Figure 3), due to its biocompatibility and physic chemical properties (cationic charge, deacetylation degree, solubil), during the last 10 years chitosan and its derivatives were well appreciated for theirs very good performance in pharmaceutical applications as:
a) Antiparasitic agent,
b) Antimicrobial agent,
c) Biomaterial,

d) Wound healing,

e) Biomedical adhesive,

f) Tissue engineering agent,

g) Antitumoral agent and

h) Antioxidant agent.

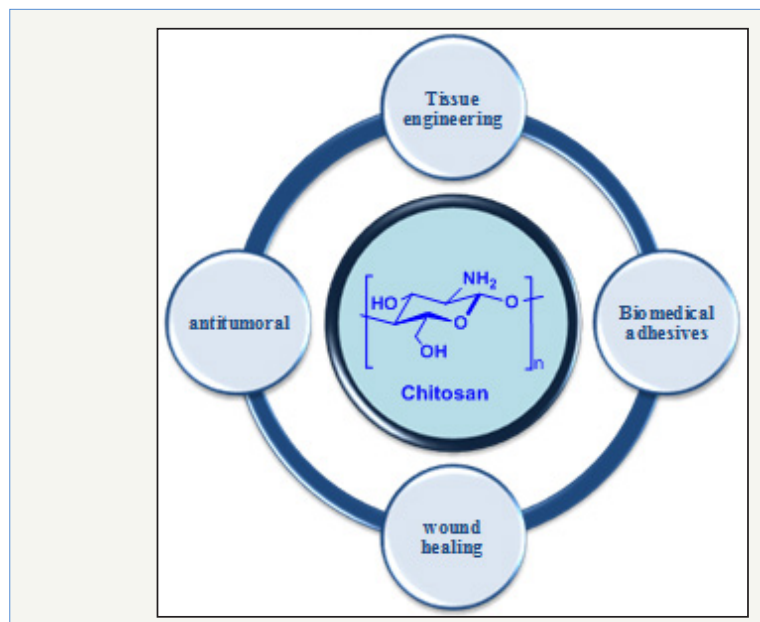

Figure 3: List of the most important pharmaceutical applications of chitosan and its derivatives.

Recently, in very interesting reviews it was given an overview concerning the last advances in pharmaceutical application of 
chitosan $[4,17]$. It was principally mention the impact of chitosan and derivatives in drug delivery, wound dressing and biomedical applications. In some publications, chitosan biomaterial based hydrogels form was efficiently applied for tissue engineering and anticancer drug delivery [18-21]. As a general rule, modern biomaterial based on chitosan (2D and 3D scaffolds such as sponge, foam, gels fibers or film) are more and more developed for tissue and bone engineering [21,22]. The last but not the least application using chitosan and derivatives is then the anticancer field. For example it was above all established the potential application of $\mathrm{N}$-trimethyl $\mathrm{N}$-octyl-chitosan for the high controlled release of hydroxycamptothecin derivatives as anticancer drug [23]. In the same way, others works has shown the antitumor drug delivery application of a new hybrid magnetic nanoparticle based on maltosyl chitosan derivative [24].

Finally, it was clearly mentioned in several studies the real impact of chitosan in cancer chemoprevention due to the specific micronutrients encapsulation with chitosan derivatives in order to:

a) Increase drug delivery in blood and,

b) Reduce side effects on healthy cells [25-28]

\section{References}

1. Delattre C, Laroche C, Michaud P (2008) Bacterial and fungal polysaccharides produced by fermentation-an overview Advances in fermentation Technology Asiatech Publishers Inc., New Delhi, India, 18: 483-522.

2. Mati Baouche N, Elchinger PH, De Baynast H, Pierre G, Delattre C, et al. (2014) Chitosan as an adhesive. European Polymer Journal 60: 198-213.

3. Peter MG, Kegel G, Keller R (1986) Structural studies on sclerotized insect cuticle In: Muzzarelli, Jeuniaux, Gooday (eds.), Chitin in nature and technology. Plenum Press, USA, pp. 21-28.

4. Laroche C, Delattre C, Mati Baouche N, Salahd R, Violeta Ursu A, et al. (2017) Bioactivity of Chitosan and Its Derivatives. Curr Org Chem.

5. Kurita K (2006) Chitin and chitosan: Functional biopolymers from marine crustaceans. Marine Biotechnol 8(3): 203-226.

6. Kumar MNVR, Muzzarelli RAA, Muzzarelli C, Sashiwa H, Domb AJ (2004) Chitosan chemistry and pharmaceutical perspectives. Chemical Reviews 104(12): 6017-6084

7. Ercelen S, Zhang X, Duportail G, Grandfils C, Desbrières J, et al. (2006) Physicochemical properties of low molecular weight alkylated chitosans: A new class of potential nonviral vectors for gene delivery. Colloids Surf B Biointerfaces 51(2): 140-148.

8. Desbrières J, Martinez C, Rinaudo M (1996) Hydrophobic derivatives of chitosan: Characterization and rheological behavior. International Journal of Biological Macromolecules 19(1): 21-28.

9. Pierre G, Salah R, Gardarin C, Traikia M, Petit E, et al. (2013) Enzymatic degradation and bioactivity evaluation of C-6 oxidized chitosan. Int J Biol Macromol 60: 383-392.

10. Mourya VK, Inamdar NN (2008) Chitosan-modifications and applications: Opportunities galore. Reactive and Functional Polymers 68(6): 1013-1051.

11. Sashiwa H, Shigemasa Y (1999) Chemical modification of chitin and chitosan 2: Preparation and water soluble property of $\mathrm{N}$-acylated or
N-alkylated partially deacetylated chitins. Carbohydr Polym 39(2): 127138

12. Kurita K (1986) Chemical modifications of chitin and chitosan. In: Muzzarelli RAA, Jeuniaux C, Gooday GW (Eds.), Chitin in Nature and Technology. Plenum Press, USA, pp. 287-293.

13. Verheul RJ, Amidi M, Van Der Wal S, Van Riet E, Jiskoot W, et al. (2008) Synthesis, characterization and in vitro biological properties of O-methyl free N,N,N-trimethylated chitosan. Biomaterials 29(27): 3642-3649.

14. Thanou MM, Kotzé AF, Scharringhausen T, Lueßen HL, De Boer AG, et al. (2000) Effect of degree of quaternization of N-trimethyl chitosan chloride for enhanced transport of hydrophilic compounds across intestinal Caco-2 cell monolayers. J Control Release 64(1-3): 15-25.

15. Kotze AF, Thanou MM, Luessen HL, De Boer ABG, Verhoef JC, et al. (1999) Effect of the degree of quaternization of $\mathrm{N}$-trimethyl chitosan chloride on the permeability of intestinal epithelial cells (Caco-2). Eur J Pharm Biopharm 47(3): 269-274.

16. Thanou MM, Verhoef JC, Junginger HE (2001) Chitosan and its derivatives as intestinal absorption enhancers. Adv Drug Del Rev 50(Suppl 1): S91-S101.

17. Bashir S, Teo YY, Ramesh S, Ramesh K, Khan AA (2015) N-succinyl chitosan preparation, characterization, properties and biomedical applications: A state of the art review. Reviews in Chemical Engineering 31(6): 563-597.

18. Kamoun EA (2016) N-succinyl chitosan-dialdehyde starch hybrid hydrogels for biomedical applications. Journal of Advanced Research $7(1): 69-77$

19. Ajish JK, Ajish Kumar KS, Chattopadhyay S, Kumar M (2016) Glycopolymeric gel stabilized N-succinyl chitosan beads for controlled doxorubicin delivery. Carbohydr Polym 144: 98-105.

20. Rogalsky A, Kwon HJ, Lee Sullivan P (2016) The rheological injectability of N-succinyl-chitosan solutions. Carbohydr Polym. 151: 1082-1090

21. Cheng N, Cao X, Peng HT (2011) Chitosan: A promising biomaterial for tissue engineering and hemorrhage control. Focus on Chitosan Research chapters, pp. 49-82.

22. Croisier F, Jérôme C (2013) Chitosan-based biomaterials fro tissue engineering. European Polymer Journal 49(4): 780-792.

23. Zhang C, Ding Y, Yu L, Ping Q (2007) Polymeric micelle systems of hydroxycamptothecin based on amphiphilic N-alkyl-N-trimethyl chitosan derivatives. Colloids and Surfaces B: Biointerfaces 55(2): 192199.

24. Alupei L, Peptu CA, Lungan AM, Desbrieres J, Chiscan O, et al. (2016) New hybrid magnetic nanoparticles based on chitosan-maltose derivative for antitumor drug delivery. Int. J Biol Macromol 92: 561-572.

25. Tan ML, Shao P, Friedhuber AM, Van Moorst M, Elahy M, et al. (2014) The potential role of free chitosan in bone trauma and bone cancer management. Biomaterials 35(27): 7828-7838.

26. Salah R, Michaud P, Mati F, Harrat Z, Lounici H, et al. (2013) Anticancer activity of chemically prepared shrimp low molecular weight chitin valuation with the human monocyte leukaemia cell line, THP-1. International Journal of Biological Macromolecules 52:333-339.

27. Kumar SP, Birundha K, Kaveri K, Devi KTR (2015) Antioxidant studies of chitosan nanoparticles containing naringenin and their cytotoxicity effects in lung cancer cells. Int J Biol Macromol 78: 87-95.

28. Botlagunta M (2016) Nutraceuticals-loaded chitosan nanoparticles for chemoprevention and cancer fatigue. Nutraceuticals. pp. 783-839. 